\title{
Uterine Artery Notching on Color Doppler Ultrasound and Roll over Test in Prediction of Pregnancy Induced Hypertension
}

\author{
Sharma Sujata $\cdot$ Singh Sohan $\cdot$ Gujral Uma $\cdot$ \\ Oberoi Upasana $\cdot$ Kaur Rajwinder
}

Received: 25 September 2009/Accepted: 4 August 2011/Published online: 14 February 2012

(C) Federation of Obstetric \& Gynecological Societies of India 2012

\begin{abstract}
Objective To study the role of uterine artery notch on color Doppler ultrasound and roll over test in prediction of PIH.

Methods 100 women with high risk pregnancies were studied for presence or absence of uterine artery diastolic notch by Doppler ultrasound at 16-28 weeks. Same women were then subjected to roll over test at 28-32 weeks.

Results The primary outcome was that uterine diastolic notching alone and combined together with roll over test shows a high specificity $(98.53 \%)$ for predicting PIH than roll over test $(76.47 \%)$ alone. PPV of uterine artery diastolic notching $(83.33 \%)$ was higher than roll over test alone (54.29\%) and both tests combined together (80\%).

Conclusion After analyzing all the results, it has been concluded that uterine artery Doppler notching is better
\end{abstract}

Sharma S., Professor · Oberoi U., Associate Professor .

Kaur R., Junior Resident

Department of Gynaecology, Government Medical College,

Amritsar, India

Singh S., Professor

Department of Radio Diagnosis, Government Medical College,

Amritsar, India

Gujral U., Associate Professor

Department of Biochemistry, Government Medical College,

Amritsar, India

Oberoi U. ( $\square)$, Associate Professor

13-C, Mata Kaulan Marg, Kashmir Avenue, Amritsar 143 001, India

e-mail: oberoiupasana@yahoo.co.in predictor for PIH than roll over test or even combined Doppler + Roll over test together.

Keywords Uterine artery notching - Color Doppler . Roll over test · Pregnancy induced hypertension

\section{Introduction}

Pregnancy induced hypertension (PIH) is the most common complication of pregnancy and it affects up to $12 \%$ of pregnancies [1]. It is one of the leading causes of maternal morbidity and mortality [2]. Also it is the leading cause in $23 \%$ of all viable low birth weight babies [3]. So prevention of PIH could have salutary effects on pregnancy out come both for mother and child.

Incidence of PIH is about 5\%. It is more common at either end of reproductive age, influenced by parity, race, and socioeconomic status, previous history of PIH and family history. It is 5 times more common in twin pregnancies especially dizygotic twins. PIH is $12 \%$ in both diabetics and in gestational diabetics.

Doppler ultrasound evaluation of uterine artery impedance in the second trimester has been used as an early screening test for preeclampsia [4]. Uterine artery Doppler wave form is unique and characterized by high diastolic flow velocities. Increased resistance to flow and development of a diastolic notch have been associated with PIH [5].

Doppler ultrasound provides a non-invasive method for the study of the uteroplacental circulation. The characteristic 
shape of uterine waveform shows a steep systolic slope, an early diastolic notch and a small amount of diastolic flow. The waveform is essentially a high resistance form in the nonpregnant state. As the pregnancy progresses, there is gradual removal of the notch and an increase in the diastolic flow, as seen by the fall in resistance index (RI).

By using the persistence of the notch of the uterine arteries as the definition of abnormality, it was found that it persists in the majority of the women diagnosed with PIH.

\section{Aims and Objectives}

The purpose of the present study is to study the predictive value of uterine artery diastolic notch on color Doppler at 16-28 weeks gestation and "Rollover" test at 28-32 weeks of gestation individually, and combined together, for prediction of PIH.

\section{Materials and Methods}

100 women with high risk pregnancies including primigravidas, women with family history of $\mathrm{PIH}$, previous history of PIH, eclampsia, APH (abruption), gestational diabetes, chronic hypertension, $\mathrm{Rh}$ incompatibility, polyhydramnios, oligohydramnios, anhydramnios, twin pregnancy, chronic nephritis, teenage pregnancy, severe anemia, elderly primigravidas, grand multipara and previous bad obstetric history were studied.

Detailed general physical examination of the women along with routine hematological investigations, blood sugar levels, ABO Rh grouping, renal function tests, hepatic function tests, fundus oculi examination, urine examination for albumin was done.

Detailed antenatal examination was done on all women. They were then subjected to Doppler ultrasound at 16-28 weeks to evaluate the presence or absence of notch in the uterine artery. Same woman was then subjected to "Rollover test" at 28-32 weeks.

The rollover test is a non-invasive office procedure. A positive test is an elevation of $20 \mathrm{~mm}$ of $\mathrm{Hg}$ or more in blood pressure when the woman rolls over from lateral decubitus to the supine position at 28-32 weeks of gestation.

\section{Observations}

Out of a total of 100 women, the number of women who developed PIH were 32 . Out of these 32 women, three were found to have gestational hypertension, 28 had preeclampsia and 1 woman developed eclampsia.

The observations were recorded considering-age, gravidity, socio-economic status, anemia, and weight relationship with $\mathrm{PIH}$. It was observed that majority of women who developed PIH were between age of 31-35 years $(66.66 \%)$, third gravidas $(58.33 \%)$, anemic (hemoglobin levels below $8 \mathrm{~g} \%$ ) $(83.33 \%)$, belonged to lower socioeconomic group (39.65\%), and had weight between 61 and $70 \mathrm{~kg}(70.37 \%)$.

Relationship of Presence or Absence of Diastolic Notch in Uterine Artery Waveform at 16-28 Weeks of Gestation to PIH

Of the 6 women who had diastolic notch, only 5 developed PIH. The test gave PPV-83.33\%, NPV-71.28\%, sensitivity $-15.63 \%$ and specificity $-98.53 \%$ (Table 1).

\section{Relationship of Rollover Test to PIH}

Of the 65 women who showed negative roll over test, 13 women developed PIH and 52 women remained normotensive, giving a NPV of $80 \%$, sensitivity $59.38 \%$, specificity $76.47 \%$ and PPV 54.29\% (Table 2).

Relationship of PIH with Rollover Test and Uterine Artery Diastolic Notch Combined Together

Both tests combined together had a PPV of $80 \%$, NPV $70.53 \%$, sensitivity $12.50 \%$ and specificity $98.53 \%$ (Table 3 ).

\section{Discussion}

In our study, out of 100 women, 32 women developed PIH (incidence-32\%) and 68 women remained normotensive throughout. Out of these 32 women, three were found to have gestational hypertension, 28 had preeclampsia and one woman developed eclampsia. This incidence is higher

Table 1 Showing relationship of diastolic notch in uterine artery waveform to PIH

\begin{tabular}{llll}
\hline $\begin{array}{l}\text { Presence/absence } \\
\text { of diastolic notch }\end{array}$ & $\begin{array}{l}\text { Women } \\
\text { developing PIH }\end{array}$ & $\begin{array}{l}\text { Women not } \\
\text { developing PIH }\end{array}$ & Total \\
\hline Notch present & $5(83.33 \%)$ & $1(16.66 \%)$ & $6(6 \%)$ \\
Notch absent & $27(28.72 \%)$ & $67(71.27 \%)$ & $94(94 \%)$ \\
Total & 32 & 68 & 100 \\
\hline
\end{tabular}

Table 2 Showing relationship of rollover test to PIH

\begin{tabular}{llll}
\hline $\begin{array}{l}\text { Result of } \\
\text { rollover test }\end{array}$ & $\begin{array}{l}\text { Women } \\
\text { developing PIH }\end{array}$ & $\begin{array}{l}\text { Women not } \\
\text { developing PIH }\end{array}$ & Total \\
\hline Positive & $19(54.29 \%)$ & $16(45.72 \%)$ & $35(35.00 \%)$ \\
Negative & $13(20.00 \%)$ & $52(80.00 \%)$ & $65(65.00 \%)$ \\
Total & 32 & 68 & 100 \\
\hline
\end{tabular}


Table 3 Showing relationship of PIH with rollover test and uterine artery diastolic notch combined together

\begin{tabular}{lllr}
\hline $\begin{array}{l}\text { Rollover test and } \\
\text { diastolic notch }\end{array}$ & $\begin{array}{l}\text { Women } \\
\text { developing PIH }\end{array}$ & $\begin{array}{l}\text { Women not } \\
\text { developed PIH }\end{array}$ & Total \\
\hline Positive & 4 & 1 & 5 \\
Negative & 28 & 67 & 95 \\
Total & 32 & 68 & 100 \\
\hline
\end{tabular}

than most studies done previously, as our study was carried out in a tertiary centre, taking only high risk pregnancies.

Incidence of $\mathrm{PIH}$ as reported by various authors is 5-10\% [6], 11\% [7], 12-20\% [8] and 3-14\% [9].

The sensitivity of uterine artery diastolic notch in our present study was found to be $15.63 \%$, specificity $98.53 \%$, PPV $83.33 \%$ and NPV $71.28 \%$. Our result is comparable to that found in study by Bewley et al. [10] (sensitivity $24 \%$, specificity 95\%) and by Zimmerman et al. [11] (sensitivity 22\%, specificity 90\%). The disparity in PPV and NPV of our study and in various studies done previously is probably because of variation in the study population.

The sensitivity of roll over test was found to be $59.38 \%$, specificity $76.47 \%$, PPV $54.29 \%$ and NPV $80.00 \%$. These observations are in accordance with the study done by Kuntz [12]. Combined together the two tests had sensitivity $12.50 \%$, specificity $98.53 \%$, PPV $80.00 \%$ and NPV $70.53 \%$.

Until there is a better knowledge of the etiology and pathogenesis of PIH, a preventive approach is suggested. Though it is not conclusive that rollover test and the presence/absence of diastolic notching in the uterine artery have a positive role in predicting the occurrence of $\mathrm{PIH}$, combined together they still form an important part of the investigative process for early detection and timely management of disease process.

\section{Conclusion}

The incidence of PIH in the study is $32 \%$. Out of these 32 women, three were found to have gestational hypertension, 28 had preeclampsia and one woman developed eclampsia. $68 \%$ of the women were normotensive.

PIH was seen more in the age group of 31-35 years $(66.67 \%)$, para $3(58.33 \%)$, maximum with hemoglobin less than $8 \mathrm{~g} \%$.

Diastolic notch on uterine artery Doppler ultrasound as a predictor for development of PIH was found to have: sensitivity (15.63\%), specificity (98.53\%), PPV $(83.33 \%)$, NPV $(71.28 \%)$.

Rollover test as a predictor for development of PIH was found to have: sensitivity $(59.38 \%)$, specificity (76.47\%), PPV (54.9\%), NPV (80.00\%).
Both the tests combined together, when used for the prediction of development of PIH were found to have: sensitivity (12.50\%), specificity (98.53\%), PPV $(80.00 \%)$, NPV $(70.53 \%)$.

After analysis of the results and comparison with the reports of previous workers, it has been established that uterine artery diastolic notching shows a high specificity for predicting $\mathrm{PIH}$ than rollover test. Combined together both the tests also show specificity as high as uterine artery notching alone. PPV of uterine artery diastolic notching is found to be $83.33 \%$, which is higher than the PPV of both tests combined together $(80.00 \%)$. Rollover test shows a much lower PPV of $54.29 \%$.

This is, by and large, an endeavor to assess the predictive value of two tests for development of PIH. Our results don't exactly correspond with any of the international studies conducted previously. This can be attributed to the fact that our study population includes only high risk cases attending the out-woman department of a tertiary care centre in an Indian setup.

\section{References}

1. Ales KL, Clarson ME. In search of the true inception cohort. J Chronic Dis. 1987;40:815-81.

2. Lehmann DK, Mobic WC, Miller JM Jr, et al. The epidemiology and pathology of maternal mortality charity hospital of Louisiana in New Orleans 1965-1984. Obstet Gynaecol. 1987;69:833-40.

3. Ales KL, Frayer W, Hawks G, et al. Development and validation of a multivariate predictor of mortality in very low birth weight. J Clin Epidemiol. 1988;41:1095-103.

4. Harrington K. et al. The use of uterine artery Doppler in pregnancy induced hypertensive disorders. Switzerland: Obstetrics and Gynaecology, MD Kaunus University; 1997. p. 16-8. www.gfmer.ch/Endo/Fellows_11/Pdf/Doppler_pregnancy.pdf. Cited April 2001.

5. North RA, Ferrier C, Long D, et al. Uterine artery Doppler flow velocity waveforms in the second trimester for the prediction of preeclampsia and fetal growth retardation. Obstet Gynaecol. 1994;83:378-86.

6. O'Brien E, Beevers D, Marshall H. ABC of hypertension. 3rd ed. London: British Medical Association; 1995.

7. Hartikainen LA, Aliharmi RH, Rantakallio PT. Hypertention in pregnangy. A cohort study of epidemiological associations and outcomes of pregnancies with hypertensive disorders. Obstet Gynaecol. 1998;17:31-41. http://www.informahealthcare.com/ doi/abs/10.3109/10641959809072236.

8. ACOG Practice Bulletin No. 33. Diagnosis and management of pre-eclampsia and eclampsia. Obstet Gynaecol. 2002;99:159-66.

9. Finger I, Jastrow N, Irion O. Preeclampsia: a danger growing in disguise. Int J Biochem Cell Biol. 2008;40:1979-83.

10. Bewley S, Cooper D, Campbell S. Doppler investigation of uteroplacental blood flow resistance in 2nd trimester, a screening study for preeclampsia and IUGR. Br J Obstet Gynaecol. 1991;98:871.

11. Zimmerman P, Eirio V, Kosikinen J, et al. Ultrasound. Obstet Gynaecol. 1997;9:330-8.

12. Kuntz WD. Supine Pressor (rollover) test: on evaluation. Am J Obstet Gynaecol. 1980;137:764-8. 